\title{
Atemporalización y presentificación del mundo social en la sociología contemporánea
}

\author{
Ramón RAMOS TORRE \\ TRANSOC-Universidad Complutense de Madrid \\ rrt@cps.ucm.es
}

Recibido: 03-06-2013

Aceptado con modificaciones: 15-01-2014

Aceptado: 31-01-2014

\section{Resumen}

La sociología contemporánea ha reconocido el papel relevante del tiempo en el análisis del mundo desbocado en que vivimos. Este interés creciente resulta, con todo, paradójico ya que el reconocimiento de la centralidad sociológica del tiempo va de la mano de la denuncia de su desaparición o, al menos, de su radical desestructuración y disfuncionalidad. Resulta así que ese tiempo reivindicado se convierte en un tiempo desaparecido. Este trabajo pretende reconstruir este diagnóstico paradójico en sus tres variantes fundamentales que se denominan de la atemporalización, la presentificación y la espacialización. Una vez analizadas en sus distintas manifestaciones, se procede a su crítica y al esbozo de una alternativa que no caiga en los errores detectados.

Palabras clave Sociología del tiempo, atemporalidad, presentismo, espacialización, aceleración

\section{Atemporality and presentism of the social world in contemporary sociology}

\begin{abstract}
Contemporary sociology has recognized the important role of time in the analysis of the runaway world we live in. This growing interest is, however, ironic because the recognition of the sociological centrality of time goes with the denunciation of its disappearance or at least its radical disorganization and disfunctionality. As a consequence claimed time turns into missing time. This paper seeks to rebuild this paradoxical diagnosis in its three core variants: atemporality, presentism and spacelization. After analyzing its various sociological manifestations, these are subject to criticism and an alternative that does not fall into the detected errors is outlined.
\end{abstract}

Key words: Sociology of time, atemporality, presentism, spacelization, acceleration

\section{Referencia normalizada}

Ramos Torre, R. (2014). “Atemporalización y presentificación del mundo social en la sociología contemporánea”. Política y Sociedad, Vol.51 Núm. 1 147-176

Sumario: Introducción. 1.Espacialización, atemporalización y presentificación. 2.Sobre la atemporalización de la sociedad contemporánea. 3.Sobre la presentificación de la sociedad contemporánea. 4.Sobre la espacialización del mundo social y su ciencia. 5.¿Un tiempo enfermo?. 6.Conclusiones/remisiones. Bibliografía 


\section{Introducción}

Desde su arranque a principios del siglo pasado, la empresa de la sociología del tiempo se ha desplegado en el interior de un círculo virtuoso en el que la tarea inicial de proceder a una socialización (y sociologización) del tiempo se vio prontamente acompañada por la inversa, aunque complementaria, de temporalizar lo social (y la sociología misma). Y así, la ambición inicial, tal como la expresó Durkheim (1968) y en parte Mead (1980), de rescatar de las manos de los filósofos el viejo problema del tiempo y ponerlo en manos de la ciencia social, fue pronto acompañada por una creciente atención por los aspectos puramente temporales de los fenómenos sociales, subrayando su relevancia para su cabal descripción y eventual comprensión-explicación. Esa alma doble se ha mantenido siempre viva, aunque sometida a tensiones y desequilibrios puntuales. Desde luego, persiste en la actualidad, como lo muestra fehacientemente la obra de Barbara Adam, interesada a la vez en fundamentar una aproximación sociológica al problema del tiempo (Adam 1990 y 2004) y en desarrollar una sociología profunda y explícitamente temporalizada (Adam 1995 y 1998).

El resultado alcanzado se puede retratar, utilizando las categorías propuestas en su momento por Herminio Martins (1992), como la conjunción de una doble temporalización: temática, por un lado; sustantiva, por el otro. De la primera da cuenta la presencia de la perspectiva temporal en el seno de las distintas sociologías especiales; de la segunda, la relevancia del tiempo en la constitución de la teoría sociológica contemporánea. Con todo, este retrato no es todavía suficiente para dar cuenta de la situación actual. Y es que, como es norma en las historias sustanciosas, ocurre que al final el éxito del tiempo ha desembocado en aparente derrota, de modo que ese mismo tiempo, atendido y subrayado como aspecto crucial del mundo social, se ha convertido en tiempo desaparecido ${ }^{1}$.

En este trabajo voy a reconstruir las evidencias en las que cabe apoyarse para alcanzar un diagnóstico así, estableciendo como punto de arranque (1) el diagnóstico ejemplar de Fredric Jameson en la década de los '80, y mostrando los variados diagnósticos sobre la actualidad que subrayan (2) la atemporalización, (3) la presentificación o (4) la espacialización del mundo social, para proceder a continuación (5) a su crítica y (6) a apuntar una alternativa.

${ }^{1}$ Lo anterior es un resumen comprimido de lo expuesto en Ramos (2009).Véase Ramos (1995 y 1998) para un resumen muy sintético de la estructura temporal del tiempo moderno con las referencias bibliográficas pertinentes. 


\section{Espacialización, atemporalización y presentificación.}

Se puede utilizar el conocido trabajo de Fredric Jameson (1995) sobre la posmodernidad o la lógica cultural del capitalismo como origen y a la vez expresión del largo debate sobre el tiempo social en el mundo contemporáneo que pretendo reconstruir ${ }^{2}$. Aparecido en la New Left Review en 1984 y, en su versión definitiva en forma de libro, en 1991, puede considerarse como un diagnóstico ejemplar por su capacidad para concentrar en pocas páginas lo que serían más tarde líneas de análisis relativamente autónomas. En efecto, una lectura cuidadosa de ese trabajo permite detectar la copresencia de tres diagnósticos sobre la deriva cultural del espacio-tiempo del capitalismo contemporáneo, finisecular o posmoderno: un primero que destaca un cambio de época que invierte la temporalización del mundo característica del primer capitalismo o capitalismo clásico, convirtiéndola en una unilateral espacialización de la experiencia (Jameson 1995: 40 ); un segundo diagnóstico que desvela la caída en la atemporalización radical de la experiencia (ibid.: 52, 66); y un tercero que apunta hacia la presentificación de la realidad (ibid.: 64-6). Jameson presenta esos tres diagnósticos como caras o aspectos de un diagnóstico único:

"Si el tiempo, en efecto, ha sido reducido a la violencia más puntual y al mínimo cambio irrevocable de una muerte abstracta, entonces podemos quizá afirmar que en lo posmoderno el tiempo ha devenido de todos modos espacio" (Jameson 2000: 32; cursiva mía).

Se fijan, pues, las tres caras de una misma realidad cultural $-y$ los tres soportes de su crítica de la posmodernidad. Pero, como muestra la evolución posterior de ese debate, no es preciso que los tres vayan de la mano o sean aspectos de un diagnóstico único ${ }^{3}$. Podemos y debemos diferenciarlos. Por espacialización hay que entender el proceso de sustitución de las categorías temporales por las categorías espaciales, ya sea como vía única, ya como vía eminente, para dar cuenta de la experiencia socio-cultural de la (pos-, ultra-, sobre-, etc.) modernidad. Todo debate en el que se contraponga la categorización temporal a la espacial y se presente la primera como

2 Jameson ha vuelto de forma directa al tema en un trabajo de publicación reciente (Jameson 2003), en el que reafirma su diagnóstico sobre la primacía del espacio y la finalización del tiempo en la fase posmoderna del capitalismo cultural. Agradezco a David Sánchez Usanos haberme llamado la atención sobre ese texto; véase Sánchez Usanos (2010).

${ }^{3}$ Jameson (2003) apunta también a la corporeización (o primacía y protagonismo creciente del cuerpo) como otro aspecto de la cultura tardo-capitalista que acaba con el tiempo y apuesta por el espacio. Sería interesante un estudio sistemático de la propuesta posmoderna sobre el complejo formado por la atemporalización, espacialización y corporeización de la ciencia social. 
propia de un mundo social ya ido y la segunda como exigencia del mundo emergente o contemporáneo se sitúa en el plano de la problemática de la espacialización propuesto por Jameson. Por su parte, la atemporalización comporta simplemente la desaparición de la continuidad temporal, la duración, los intervalos ordenados y la sucesión, sustituidos por la fragmentación, la instantaneidad y el caos temporal. Por último, la presentificación no arrastra consigo necesariamente la espacialización o la atemporalización en los sentidos que se acaban de fijar, sino que se limita a centrar la atención en la reducción de la experiencia del tiempo a la de un presente (puntual o alargado, según se verá) desgajado de sus horizontes de futuro y pasado que o bien desaparecen, o bien se comprimen hasta el punto de perder toda extensión y significación.

En el marco de estas distinciones se puede hacer una incursión por el territorio académico poblado por las variadas propuestas sobre el destino del tiempo en la sociedad contemporánea, ya sean o no hijas de la influencia del diagnóstico de Jameson, y ya se aproximen mucho, poco o nada a la matriz marxista en las que inicialmente se generaron. Comenzaré por las que hacen mayor énfasis en la atemporalización, retengan o no las otras dos caras del diagnóstico de Jameson. Más adelante se abordarán las propuestas más centradas en (o relevantes para) la presentificación y la espacialización.

\section{Sobre la atemporalización de la sociedad contemporánea.}

En su conocido trabajo sobre La Condición de la Posmodernidad Harvey (1998) asume y radicaliza el diagnóstico de Jameson. Supone, como éste, que nos hemos adentrado en la nueva época cultural de la posmodernidad y que para comprenderla es preciso atender a la lógica de reproducción ampliada del capital. Lo distintivo de la nueva situación sería una aceleración y radicalización del proceso de compresión espacio-temporal propio del capitalismo desde sus inicios históricos. Lo propio de ese mundo emergente es una catastrófica desestructuración de la realidad y la experiencia, que no sólo conlleva la atemporalización y la presentificación, sino también la ruina del espacio ordenado del primer capitalismo. De ahí la radicalización del diagnóstico de Jameson que comporta la tesis de la compresión espaciotemporal; a su entender:

"la intensidad de la compresión espacio-temporal en el capitalismo occidental a partir de la década de 1960, con todos sus rasgos congruentes de transitoriedad y fragmentación, [...] parece revelar un contexto de experiencias que convierte a la condición posmoderna en algo especial. Pero si situamos esta

\footnotetext{
${ }^{4}$ Para una lectura alternativa de la obra de Harvey, en la que se desatienden como escasamente significativas las propuestas de La Condición de la Posmodernidad, véase Castree (2009).
} 
condición en su contexto histórico, como parte de una historia de olas sucesivas de compresiones espacio-temporales generadas por las presiones de la acumulación capitalista en su constante afán de aniquilamiento del espacio por el tiempo y la reducción de los tiempo de rotación, al menos podemos situar la condición de la posmodernidad en el espectro de una situación accesible al análisis y la interpretación materialista histórica” (Harvey 1998: 339; cursiva RR).

La compresión del tiempo significa el triunfo en todos los planos (no sólo en el económico) de la experiencia de lo transitorio, lo volátil, lo efímero, lo instantáneo, lo desechable, pero también la emergencia de un presente encerrado en sí mismo, la "sensación de horizontes temporales que colapsan" (ibid.: 321) y la consecuente "pérdida de un sentido de futuro" (ibid.; 322): caída, pues, en la atemporalidad y la presentificación extremas. Pero esta caída no va de la mano de una espacialización de la experiencia. El espacio del capital también colapsa, fragmentándose, horadando las fronteras que lo separaban y ordenaban y rompiendo las distancias: nada está aquí o allí, lejos o cerca, dentro o fuera. Genera así su paradoja central: el espacio fragmentado y destruido es sustituido por la relevancia del lugar en el marco de un capitalismo que genera un espacio económico altamente unificado:

"cuanto menos importantes son las barreras espaciales, mayor es la sensibilidad del capital a las variaciones del lugar dentro del espacio, y mayor el incentivo para que los lugares se diferencien a fin de hacerse atractivos para el capital. El resultado ha sido producir una fragmentación, una inseguridad y un desarrollo desigual efímero en un espacio económico global altamente unificado de flujos de capital” (ibid.: 327).

Las propuestas de Castells en este campo de debates, aunque inspiradas entre otros en Harvey ${ }^{5}$, son mucho más sosegadas, aunque no por ello analíticamente más claras o fundamentadas. En el marco de su diagnóstico sobre la emergencia de la sociedad informacional en red y las transformaciones profundas del capitalismo contemporáneo ligadas a la revolución de las tecnologías de la información y la comunicación (TICs), Castellls opta por una variante del diagnóstico de Jameson. Por un lado, enfatiza el triunfo del espacio sobre el tiempo en una fórmula muy sumaria: "el espacio organiza al tiempo en la sociedad red" (Castells 1997: 410). Esta primera formulación es especificada en otra formulación muy cargada en términos jamesiano-historicista en la que se plantea que "en nuestra sociedad el espacio determina al tiempo, con lo que se invierte una tendencia secular: los flujos inducen el tiempo atemporal, los lugares se circunscriben al tiempo" (ibid.: 500). Hay, pues, una inversión secular (paso de la temporalización a la espacialización),

\footnotetext{
${ }^{5}$ Aunque también son relevantes las propuestas de Lash y Urry (1994) de quienes se recoge la distinción entre ‘tiempo del reloj', ‘tiempo instantáneo' (es decir, el ‘tiempo atemporal' de Castells) y 'tiempo glacial', con el consiguiente esquema de periodificación histórica: sustitución del primero por los otros dos.
} 
pero esa inversión todavía no se halla universalmente cumplida pues se mantienen enclaves todavía temporalizados: los lugares que subsisten en los intersticios de la sociedad-red. En cualquier caso, el nuevo espacio dominante, o espacio de los flujos (ibid.: 445), domina sobre el tiempo, eliminándolo o desestructurándolo en los ámbitos estratégicos que conforma. Surge así lo que Castells (ibid.: 499) denomina el "tiempo atemporal”. Su semántica es básicamente la de la atemporalidad: apoteosis de lo instantáneo o del tiempo 'real', eliminación consecuente de la experiencia de la duración, simultaneización de la experiencia, desordenación de las secuencias temporales, reino de lo efímero que se convierte, además, en fuente paradójica de la experiencia de una eternidad ficticia (o "efimeridad eterna": ibid: 502). Triunfo, pues, rotundo de la atemporalidad con algún apunte sobre la emergencia de una cultura del acontecimiento y del presente encerrado en sí mismo y sin historia, si se atiende a las características de la realidad virtual que construyen los medios de comunicación (prensa, pero sobre todo TV) (ibid.: 496) ${ }^{6}$.

Este diagnóstico, que enfatiza la desestructuración del tiempo roto y destruido por la experiencia del instante y el desorden de la sucesión, es reiterado en trabajos más recientes que analizan la nueva cultura de la comunicación por móvil: " $\mathrm{La}$ comunicación móvil también potencia el tiempo atemporal entendido como la temporalidad que caracteriza la sociedad en red" (Castells et al 2006: 268; cursiva Castells). Castells es, pues, claro y definitivo: sobre el nuevo mundo del capitalismo en red y de las TICs reina la atemporalidad; sólo en los viejos espacios de los lugares desconectados del espacio de los flujos sigue rigiendo un tiempo, el "tiempo del reloj”, que dura, ordena y proporciona continuidad; y sólo en muy circunscritos medios sociales, donde surgen nuevos movimientos sociales en pos de la identidad, emerge un tiempo que va más allá de ambos, el "tiempo glacial” (Castells 1997: 502) -tiempo sobre el que Castells es más bien sobrio y poco expresivo.

El diagnóstico de la sociología crítica de Bauman sobre el mundo social del último capitalismo atiende también al tiempo, legándonos un relato de lo que parece una caída en los infiernos. Según propone, en el mundo del capitalismo posmoderno en que vivimos estamos abocados a "soportar una vida bajo un estado de incertidumbre que es permanente e irreductible” (Bauman 2001: 32). Nos arrastra en este sentido la desregulación, la volatilidad, la discontinuidad de las trayectorias vitales y laborales, la falta de asideros colectivos (comunidad, familia, barrio) que generen seguridad y el dominio de una cultura limitada a ser una "colección de instantáneas" administrada por "una identidad-palimpsesto" (ibid.: 36). Estamos en una sociedad de riesgo a la que corresponde una vida de riesgo. Es obvio que en ese entorno la experiencia temporal del mundo se convierte en un problema mayor.

Bauman (2000: 110) asegura que "la modernidad es el tiempo en el que el tiempo tiene una historia", lo que quiere decir que es entonces cuando hace su propio desplie-

\footnotetext{
${ }^{6}$ Para una reconstrucción y valoración crítica más sistemática de estas propuestas de Castells remito a Ramos (1999).
} 
gue, diferenciándose del espacio propiamente y haciéndose progresivamente con la realidad hasta llegar a lo que parece su suicidio contemporáneo. En efecto, la revolución de los transportes, que viene de la mano de la revolución industrial capitalista, lleva a la separación del tiempo y el espacio: tal es el resultado firme de la nueva experiencia de la velocidad. Ambos, espacio y tiempo, están entonces ordenados, confiriendo un sentido de seguridad y permanencia a la primera modernidad burguesa de propietarios, Estados y fábricas. Todo esto se derrumba tras el paso a la nueva fase de la modernidad ligera, fase en la que el tiempo desatado acaba anulando el espacio:

"El cambio en cuestión es la nueva irrelevancia del espacio, que se hace pasar por una aniquilación del tiempo. En el universo del software, el espacio puede ser atravesado literalmente en no-tiempo; la diferencia entre 'allá lejos' y 'justo aquí' queda cancelada. Y de este modo el espacio cuenta poco o no cuenta nada” (ibid.: 117).

Pero anulado el espacio (la distancia, la separación, la frontera), el tiempo acaba destruyéndose a sí mismo. La propuesta de Bauman retrata la caída de los modernos en la nada de la realidad. El discurso del último día hace su aparición:

"El tiempo instantáneo, insustancial del mundo software es también un tiempo inconsecuente. 'Instantaneidad' significa realización inmediata, 'on-thespot', pero también consumación inmediata y desvanecimiento del interés. La distancia temporal que separa el comienzo del final se estrecha o desvanece; las dos nociones [...] han perdido mucho de su sentido [...]. Sólo hay 'momentos': puntos sin dimensiones. ¿Pero un tiempo así, un tiempo con la morfología de un agregado de momentos, sigue siendo tiempo, 'tal como lo conocemos'? La expresión 'momento de tiempo' parece, al menos en ciertos aspectos vitales, un oxímoron. ¿Quizás, tras haber matado al espacio como valor, el tiempo se haya suicidado? ¿No fue acaso el espacio la primera baja en la frenética carrera del tiempo hacia su auto-aniquilación?” (ibid.: 118-9).

¿Ya ha ocurrido ese suicidio? ¿Nos encontramos tras el colapso de la realidad, producto de la conspiración densa del capitalismo, la posmodernidad y la modernidad ligera? En realidad, todavía no: la condena queda aplazada hacia "el horizonte de desarrollo de la modernidad ligera” (ibid.: 119). Con todo, el dominio de lo ligero lleva a una entronización de lo móvil, rápido, volátil, momentáneo; a una estetización de la existencia de la mano del consumo; a la ruina del principio de dilación o procastinización que permitía el sacrificio del presente en aras de un futuro mejor; a una presentificación que rompe los horizontes temporales.

"Los hombre y mujeres de hoy en día se distinguen de sus padres y madres por vivir en un presente que 'quiere olvidar el pasado y ya no parece creer en el futuro' (Guy Debord). Pero la memoria del pasado y la confianza en el futuro han sido los dos pilares sobre los que descansaban los puentes morales y culturales entre la transitoriedad y la durabilidad, la mortalidad humana y la inmortalidad de las realizaciones humanas, al igual que entre la asunción de responsabilidades y la vivencia del momento” (ibid.: 128-9). 
Bauman participa, pues, del discurso de la atemporalización radical que se combina con argumentos sobre la desespacialización del mundo y la presentificación de la existencia. Sus propuestas se acercan a las de Richard Sennet, uno de sus autores favoritos y más citados (lo inverso también es cierto: Sennet y Bauman mantienen el viejo principio de reciprocidad). Pero esa proximidad no es identificación: donde Bauman se extrema hasta alcanzar el discurso de la atemporalización, Sennet se esfuerza en limitarse a un discurso en el que se enfatiza la problematicidad del tiempo del nuevo capitalismo, no su volatilización. Ya en La corrosión del carácter, sus espléndidos e imaginativos análisis de los relatos de vida de trabajadores conducían a la tesis general que desvelaba que "la ansiedad personal sobre el tiempo está profundamente entrelazada con el nuevo capitalismo" (Sennet 2000: 101). Esa ansiedad resulta de los tres rasgos propios del nuevo capitalismo que Sennet, a la sombra de Bauman, denomina ligero: la cultura del plazo corto, la relevancia del 'potencial' frente a la solidez del oficio y el protagonismo creciente del papel de consumidor frente al de productor-trabajador. Es evidente que ese tipo de sujeto que reclaman las nuevas instituciones económicas, orientado al corto plazo, amnésico, siempre dispuesto a pasar de una cosa a otra y destinado a una permanente frustración de expectativas, es un ser humano "poco frecuente" (Sennet 2006: 123), privado "del sentido de movimiento narrativo, lo que, en términos más simples, significa la conexión de los acontecimientos y la acumulación de la experiencia a lo largo del tiempo" (ibid.: 157). Que se carezca de capacidad de narrar no es cualquier cosa: supone estar incapacitado (o enfrentar dificultades casi insuperables) para interpretar la experiencia e integrar lo que ahora se hace con lo hecho en el pasado y lo por hacer en el futuro. Sennet roza el diagnóstico de la presentificación, pero no se deja atrapar en su vertiente más dramática. El tiempo no ha desaparecido; simplemente se ha hecho problemático, difícil de narrar. La experiencia sigue siendo temporal; lo que no está claro son los instrumentos institucionales y de sentido para asignarle sentido. Los personajes cuyas vidas retrata lo intentan -aunque fracasen o no lo logren plenamente.

\section{Sobre la presentificación de la sociedad contemporánea.}

La centralidad o relevancia del presente en la experiencia contemporánea del tiempo social ha sido destacada de forma reiterada y variada. Lo prueba la proliferación de adjetivos para retratar una experiencia que se considera novedosa (véase Ramos 2012: 65). Como diagnóstico de época, el presentismo ha sido propuesto por el historiador François Hartog. Según argumenta, a lo largo de la historia se han ido sucediendo distintos regímenes de historicidad que no son sino "maneras de articular pasado, presente y futuro -y darles sentido" (Hartog 2003: 118). Los regímenes anteriores articulaban la experiencia alrededor de una historia que parecía ser $\mathrm{Ma}$ gistra Vitae, o de un futuro en el que se confiaba como Progreso; el nuevo régimen se articula alrededor de la experiencia de un presente que tiene la pretensión de permanecer, se alimenta de acontecimientos que entretienen, se administra en 
tiempo real, rinde culto a lo joven, blanquea la muerte, museifica lo que acaba de ocurrir, crea lugares triviales de una memoria ligera, etc. (ibid.: 126 ss.).

Surge así el Presentismo. No está claro en el análisis de Hartog si se afirma como un régimen cabal de historicidad-temporalidad, que resuelve realmente la integración en el presente del futuro y del pasado, o más bien como una forma degenerada o patológica que segrega el presente de sus horizontes temporales, encerrándolo en sí mismo. El debate sobre la muerte del tiempo que arranca de Jameson apunta más bien en esta última dirección. Voy a centrar la atención en esa variante de presentismo que, siendo experiencia epocal, más que estructurar un nuevo régimen de historicidad-temporalidad, lo hace imposible o harto problemático. Ya se configure alrededor de un presente instantáneo, achicado y huidizo, ya alrededor de un presente ensanchado y agrandado, lo relevante es que la presentificación comporte, como en el esquema original de Jameson, el colapso del presente sobre sí mismo, su encierro, y la consiguiente falta de conexión con los horizontes de pasado y futuro. Mostraré algunas variantes.

La sociología de la aceleración es una de las corrientes actuales que desemboca más naturalmente en la temática de la presentificación. Como tal, la aceleración está ligada a la modernidad; o, dicho en la forma lapidaria de Beriaín (2008: 108), "es la forma elemental de las estructuras temporales de las sociedades modernas". Al hilo de sus indagaciones sobre la semántica de los tiempos modernos, Koselleck (2007) ha mostrado cómo, en el marco de la apocalíptica de un cristianismo sobrepasado, se constituye la auto-conciencia moderna de vivir en un mundo acelerado. Las experiencias fundamentales las brindan las tres Revoluciones (Francesa, Industrial y de los Transportes) que marcan los inicios del XIX. Desde este punto de vista, venimos viviendo y pensando la aceleración desde hace al menos dos siglos, por lo que nada de novedoso parece esconder el diagnóstico que la presenta como rasgo de época. Y sin embargo, tiene razón Harmut Rosa (2003: 27) cuando sostiene que "la modernidad tardía no es sino la sociedad moderna acelerada (y desincronizada) más allá de una posible integración”. Estamos, pues, ante un diagnóstico de la época que nos ha tocado vivir que utiliza el tiempo para indicar los problemas de integración no resueltos o irresolubles. Virilio, Rosa y Eriksen encarnan tres variantes de ese discurso que atiende a la aceleración y desemboca en la presentificación ${ }^{7}$. El complemento de este diagnóstico se puede encontrar en Connerton, que subraya la cara amnésica de ese presente triunfante.

La dromología de Virilio se ha configurado como un discurso centrado monográficamente en la velocidad y la aceleración como característica del mundo en que vivimos y fuente de todos sus males. Breuer (2009) ha mostrado la deriva del

\footnotetext{
${ }^{7}$ A estas tres variantes se puede sumar la que protagonizan los seguidores de MacLuhan. Véase el librito compilado por una de sus discípulos más activos, Derrick de Kerckhove (2003). Sus propuestas son muy cercanas a las de Eriksen. Sobre la experiencia social de la aceleración centran también sus análisis Baier (2002) y Leccardi (2009).
} 
análisis dromológico de Virilio hacia una forma extrema de nihilismo posmoderno; Connolly (2000) ha llamado la tención sobre su unilateralidad, su incapacidad para detectar los efectos ambivalentes de la velocidad. Lo sustancial de su propuesta se puede reconstruir en pocas líneas. Para Virilio, la experiencia de la velocidadaceleración lleva al "final del espacio [...], de la geografía” (Virilio 1999 a: 17, 19). Desaparecidos el espacio y la geografía, parece quedar el asidero del presente, pues "a partir de ahora, el aquí ya no existe, todo es ahora” (ibid.: 130). Pero en ese ahora escaso, inasible, falsamente explosivo, muerto, se asiste a la destrucción de los horizontes temporales o a la imposibilidad de constituirlos. El presente-ahora queda segregado, encerrado sobre sí mismo, incapacitado para ser base de ninguna experiencia propiamente dicha, pues nada acontece y todo pasa sin dejar apenas rastro (ibid.: 27). Al final, lo único que puede certificar el analista es el "movimiento en nuestra cultura hacia la nada y la desaparición” (Virilio 1984: 31). El presentismo es, evidentemente, "el accidente de los accidentes, el accidente del tiempo" (Virilio 1999 b: 81); en definitiva, la tierra del $\mathrm{mal}^{8}$.

La sociología de la aceleración de Harmut Rosa (2003) es extraña a esta inflación de imágenes, frase breves y rotundas aseveraciones sobre el final de los tiempos que dominan la prosa acelerada de Virilio ${ }^{9}$. No estamos ante la descripción de un descenso a los infiernos, aunque al final la patología temporal del presentismo haga acto de presencia. Para Rosa la aceleración es un rasgo de la modernidad que se hace todavía más vivo en su fase actual (o de la modernidad tardía). Se muestra en múltiples planos de la experiencia y responde a causas variadas. No se acomoda especialmente a ninguna de las macro-sociologías, pero es coherente con las fundamentales. Tampoco hay que magnificarla como experiencia, pues ni todo está acelerado, ni lo está en el mismo grado o de la misma manera.

Rosa destaca que, en términos temporales, la aceleración plantea dos grandes problemas. Uno es muy obvio: al desplegarse de forma desigual, genera el problema de la desincronización de los tiempos sociales de los subsistemas o de las instituciones. En el campo de la política esto es especialmente claro, como destaca Rosa (2003) en seguimiento de Scheuerman (2004): hay una preocupante desincronización de los distintos poderes políticos o una crítica desincronización entre las instancias políticas y las económicas, educativas, mediáticas, etc. El otro problema tiene que ver con una de las consecuencias típicas de la aceleración: la contracción o estrechamiento del presente. Rosa recoge la idea de Lübbe (2009) quien, por su parte, no hace sino explotar propuestas que ya estaban en Koselleck (1985). En efecto, en una primera aproximación, la contracción del presente no es sino el

${ }^{8}$ En Bertman (1998) se puede encontrar una versión más esperanzada de los 'males' contemporáneos de la velocidad, que concluye con una tabla de sus efectos ambivalentes y una optimistas propuestas de reforma social.

${ }^{9}$ En España, Josetxo Beriaín (2008) se ha convertido en el mejor receptor y continuador de las interesantes propuestas de Rosa. 
resultado de una experiencia de cambio acelerado que genera la disociación entre el espacio de la experiencia y el horizonte de la expectativa ${ }^{10}$. Las cosas vividas y aprendidas no son base para generar expectativas plausibles ya que lo que ha sido válido ayer deja de serlo hoy y, con más razón, mañana. Como tal, esta disociación es constitutiva de la modernidad y, según ya mostró Luhmann (1976), está ligada al proceso de diferenciación temporal que historiza el pasado, puntualiza el presente y abre el futuro. La dinámica de la aceleración social no la crea; se limita a agudizarla. De ahí, la experiencia contemporánea de un presente que se contrae más y más, separándose progresivamente de un pasado que deja de serle instructivo y de un futuro dominado por una incertidumbre radical. En ese marco, es donde se produce una presentificación patológica que Rosa conceptúa como "situacionismo" (Rosa 2003: 19) y que tendría el efecto de provocar una "destemporalización de la vida". El argumento es como sigue:

"la gente desarrolla una nueva perspectiva que extrañamente se ha denominado ‘temporalización del tiempo': los lapsos temporales y la secuencia y duración de las actividades o compromisos ya no están planificados sino abandonados a su deriva. Esta temporalización del tiempo, sin embargo, es equivalente a la destemporalización de la vida: la vida ya no está planeada a lo largo de una línea que se alarga desde el pasado hacia el futuro; en vez de esto, las decisiones se adoptan de 'vez en vez' según los deseos y necesidades de las situaciones y contextos” (ibid.: 19).

Prima, pues, la lógica del momento, de la situación, del ahora; por lo tanto, la lógica de un presente cuyos horizontes han desaparecido y queda encerrado en sí mismo. Estamos ante la experiencia de un presentismo que destemporaliza la vida porque destruye el tiempo ${ }^{11}$.

Próximos a estas conclusiones se despliegan los análisis de Eriksen (2001) sobre las implicaciones temporales de la sociedad de la información en la época de la aceleración. A su entender, un tiempo que se trocea, desmigaja y fragmenta en unidades cada vez menores deja de ser tiempo. Y lo mismo ocurre con un presente

${ }^{10}$ Lübbe (200) destaca también la emergencia de la experiencia de la contemporaneidad de lo no contemporáneo vivida al hilo de la coetaneidad de generaciones que han sido socializadas en mundos heterogéneos. Se trata de un tema que viene también de Koselleck (1985).

${ }^{11}$ El diagnóstico es aparece también en Leccardi (2009: 26 ss.). Por su parte, el filósofo Marramao llega a conclusiones muy semejantes sobre los efectos de la aceleración. "Vivimos una vida desencajada en relación al presente" dice Marramao (2008: 101), lo que se muestra, por un lado, en la experiencia de presentes contraídos o nulificados y, por otra, en lo que califica como delirio (vivido por neuróticos y algunos segmentos de jóvenes) de un presente falsamente eterno que no sabe salir de sí mismo. Estas propuestas de Marramao se sitúan en un punto (casi intermedio) entre los teóricos del presente contraído y nulo y los teóricos (Lipovetsky y Maffesoli) del presente eterno o de gozo. 
que queda encerrado en su laberinto, sin capacidad para durar o para proyectarse en horizontes propios. El tono de Eriksen elude el dramatismo de Virilio; gran parte de sus tópicos sobre el tiempo de la sociedad de la información y el impacto temporal de las TICs no son sino variantes de las propuestas de Castells. Pero su énfasis en el sacrificio del tiempo encerrado en un presente aduracional es más claro. Un diagnóstico de conjunto permite comprobarlo:

"el flujo sin trabas y masivo de la información en nuestro tiempo [...] está llevando como consecuencia a una situación en la que todo amenaza con convertirse en una serie histérica de momentos saturados sin un 'antes' ni un 'después', un 'aquí' y un 'allí' que los separen. De hecho, incluso el 'ahora y aquí' están amenazados, pues los momentos se suceden tan rápidamente que se hace difícil vivir en el presente. Vivimos con la atención fijada firmemente en un punto que se adentra algo así como dos segundos en el futuro. Las consecuencias de esta extrema prisa son abrumadoras: el pasado y el futuro, como categorías mentales están amenazadas por la tiranía del presente" (Eriksen 2001: 2-3; cursiva RR).

La tiranía del presente comporta la destrucción del tiempo y, de su mano, una serie de efectos perversos que son recurrentes en la sociedad de la información: cotidianeidad dominada por la prisa, primacía de la urgencia en los procesos decisionales, amontonamiento (stacking) de asuntos a la espera de ser considerados, déficit de atención en los receptores de informaciones, problemas de selección de lo relevante, disolución del saber en una información desbordante e inasimilable, etc. (ibid.: 14950).

Una escueta aproximación a las propuestas de Connerton (2009) permitirá completar el cuadro de desapariciones que son compañeras de la del presente. El tema de Connerton es la memoria/olvido. Lo peculiar de su análisis es su apuesta por conectar la preservación de la memoria con la del espacio. Siguiendo esta hipótesis, propone que, en el mundo actual dominado por el capital, el espacio se esfuma y con él la posibilidad de encontrar asideros para la memoria en sus distintas variantes (cognitiva, personal, habitual).

"La creciente escala de los asentamientos humanos, la producción de la velocidad, y la reiterada destrucción intencional del entorno construido generan una difusa, aunque poderosa y omnipresente, amnesia cultural; y todos ellos, por su parte, son el producto del proceso capitalista de producción. La modernidad, o por lo menos su componente representado por la expansión económica del proceso capitalista de producción, produce amnesia cultural no casual, sino intrínseca y necesariamente. El olvido se engendra en el seno del mismo proceso de producción, incorporado en la experiencia corporal de sus espacios de vida [life-spaces]" (Connerton 2009: 125).

La cultura del capitalismo de la velocidad y la prisa, de la destrucción 'creativa' del espacio urbano y natural, es la cultura de una amnesia que lo domina todo, acortando y encerrando el presente, y que apenas encuentra compensación en la paradójica 'hipermnesia' que proporcionan las nuevas tecnologías de la información. La nues- 
tra, concluye Connerton, es “una modernidad que olvida” (ibid.: 147), encerrada en un presente desgajado.

Al flanco de la sociología de la aceleración, y enfrentada a su orientación más bien denunciatoria y crítica, se encuentra otra sociología interesada en el presentismo cuyas conclusiones difieren tajantemente de las que se acaban de resumir. En esa variante de la sociología se asiste también a un diagnóstico de actualidad que insiste en el presentismo, pero reconstruido como una experiencia que, si bien encierra al sujeto en un ahora que se auto-contiene, no es evaluada como un menos, una pérdida o una degradación, sino como gozo o liberación. Una breve incursión por alguno de los temas de las sociologías del presente de Lipovetsky y Maffesoli permitirá dar cuenta de esta alternativa.

Es claro que los análisis de la modernidad que se han sucedido en la obra de Lipovetsky se resisten a la tentación del nihilismo y el descenso a los infiernos. Como sostiene en las páginas finales de uno de sus últimos libros sobre el tema:

"La edad presentista no es en absoluto una edad enclaustrada, encerrada en sí misma, entregada a un nihilismo exponencial” (Lipovetsky 2006: 106).

Es esto firme y constante en su obra: las formas de la modernidad (post- e hiper-) que nos ha tocado vivir sucesivamente son presentistas, pero no malditas. Sobre este fondo surgen profundas diferencias en sus sucesivos escritos. Son las que separan las tesis del presentismo hedonista y despreocupado, que se hacían a la luz en El imperio de lo efímero (Lipovetsky 1990), de las tesis sobre el presentismo paradójico (entreverado de un futuro, indeterminado y anunciador de peligros, y de un pasado museificado y re-visitado) que aparecen en Los tiempos hipermodernos (Lipovetsky 2006) -y que denomina "presentismo de segunda generación" (Lipovetsky 2006: 66). Es evidente que en esta última obra su análisis alcanza una complejidad y riqueza mayores, esforzándose en dar cuenta, en sus múltiples matices, de una época que ama y teme el futuro y no puede encerrarse en el presente, aunque lo desee. Pero aquí me interesan más las propuestas de su primera obra. Ejemplifican una variante significativa del discurso de la presentificación como derrota (en este caso, gozosa) del tiempo. Las propuestas no son sólidas, parecen (al mismo Lipovetsky posterior, sin duda alguna) ingenuas, pero son ejemplo claro de un modo de concebir la presentificación.

En El imperio de lo efímero se diagnostica que vivimos bajo el imperio de la moda y, por lo tanto, de la novedad, lo efímero, lo que gusta pero no para siempre, lo que es fuente de gozo que será seguido por otra fuente insospechada. Esto supone el triunfo de una nueva temporalidad que sustituye a la tradición y al futuro como fuente de estructuración de la realidad, esa "temporalidad que desde siempre ha gobernado la moda: el presente” (Lipovetsky 1990:300). Se trata de un presente que queda afirmado en sí mismo, totalmente emancipado de un pasado que desprecia y que apenas se inquieta por un futuro que "aparece desvaído y abierto" (ibid.: 306). No es un presente de angustia, sino de gozo, dominado por un hedonismo que, a decir de Lipovetsky está a la "búsqueda de la salvación individual en las novedades como tantos otros estímulos y sensaciones propicios a una vida rica y plena” (ibid.: 
305). ¿Qué ha quedado de aquella conjetura de Jameson (1995: 66) que, dando cuenta del presente esquizofrénico del capitalismo posmoderno, proponía un sujeto que podía oscilar entre la angustia y "la intensidad intoxicadora o alucinatoria de la euforia”? Lipovetsky destina la presentificación al gozo; su elogio del carpe diem no lo es de un refugio en el que guarecerse de sinsabores, sino de una vida plena y autoafirmativa $^{12}$.

Los análisis de Maffesoli sobre el mundo de la socialidad contemporánea proponen también un presentismo hedonista y despreocupado, que acepta y goza la heterogeneidad de la vida y se abandona en brazos de un ahora que se quiere eterno. Lo que llama la atención de Maffesoli es la relevancia contemporánea de un estarjuntos mediado emocionalmente que va más allá de, y no es reductible a, lo social basado en el entendimiento y el acuerdo entre partes. Lo llama lo trágicodionisíaco ${ }^{13}$ y constituiría el rasgo propio de los tiempos que contemplan el ocaso de los grandes proyectos, la ruina del sueño de la razón uniformante y, en definitiva, el declive de una modernidad cansada. En ese marco, lo que cuenta es el hedonismo del ahora, un abandonarse a "la calmada pasión del presente, el deseo de vivir sin preocuparse demasiado del provenir [...]; lo que ocurra mañana importa poco desde el momento en que se puede gozar, aquí y ahora, de lo presente" (Maffesoli 2000: 57). La época que vivimos sería, según este diagnóstico, la del presentismo del gozo en busca del instante eterno que todo lo llena. Esto es lo nuevo y lo que desplaza a la vieja temporalidad volcada en la tarea absurda de dominar el futuro.

\section{Sobre la espacialización del mundo social y su ciencia.}

La propuesta de Jameson sobre la deriva espacializante del régimen de vida posmoderno ha conocido un destino paradójico en la ciencia social crítica. Tal como fue enunciada, pretendía denunciar una degradación de la vida social cuyas víctimas eran los sujetos que perdían la historicidad y la arquitectura temporal del mundo. Como ha puesto de relieve Doreen Massey (2005: cap. 7), ese diagnóstico-denuncia se asentaba en un dualismo implícito -fuertemente arraigado en la cultura crítica y denunciado en su momento por Foucault- que identificaba el tiempo con un más (la vida, lo creativo, la emancipación) y el espacio con un menos (la muerte, la repetición, la sujeción). La pérdida del tiempo y la caída en el espacio significaban, en

12 Partiendo de presupuestos diferentes, Brodowsky et al (2008) llegan a tesis semejantes sobre la orientación a un presentismo de gozo de la subcultura gay.

${ }^{13}$ El recurso a lo trágico en este contexto de análisis en el que se intenta fundamentar la experiencia posmoderna del instante eterno me parece arbitrario, aunque es el resultado último de una línea de publicaciones emprendida por Maffesoli desde los años '80 (véase Maffesoli 1985 y 1996). 
consecuencia, la ruina de la vida, la creatividad y la emancipación. El espacio era un infierno helado posterior al desastre de la historia.

El tópico ya había encontrado fuertes resistencias en la antropología, por lo menos desde los tiempos de Lévi-Strauss. Sus conocidas críticas del privilegio 'humanista' de la historia y su consecuente rechazo de la idea de los pueblos 'sin historia' (Lévi-Strauss 1962) engendraron múltiples variantes entre las que la más rotunda fue la de Fabian (1983) y su denuncia de la antropología como un saber alócrono ${ }^{14}$ que expulsa a las otras culturas del presente en el que viven, para situarlas en algún pasado o en épocas históricas anteriores a las del antropólogo que las observa, describe y analiza. El infierno no tiene por qué ser el espacio o lo que se da a la vez, sino que lo puede ser el tiempo, es decir, lo que se presenta como sucesión e historia.

Este contra-tópico encontrará acogida y acomodo entre otros científicos sociales -y especialmente entre los geógrafos, los proponentes de los estudios culturales o los teóricos de la globalización. Es así como al legado de Jameson se le da, en una parte sustantiva, la vuelta: no sólo porque la denuncia de la espacialización se convierte en su elogio, sino también porque ese elogio se construye en contra de un tiempo que ha dejado de ser clave de la emancipación crítica. La publicación de Geografías Posmodernas de Edward Soja a finales de los '80 firma el acta de nacimiento de una nueva (en principio posmoderna) ciencia social que reivindica el espacio de una forma que, queriéndolo o sin querer, le da la vuelta a lo implícito en el argumento de Jameson. En efecto, donde había distanciamiento crítico, hay ahora aceptación; si el mundo está espacializado, la ciencia social crítica debe reconformarse en consecuencia:

"la posmodernidad, la posmodernización y el posmodernismo parecen ser formas adecuadas de describir la contemporánea restructuración cultural, política y teorética, y de destacar la reafirmación del espacio que está entremezclada complejamente con ella” (Soja 1989: 5; cursiva RR).

Comienza así el 'giro espacial' en el que, a gusto o a disgusto, se ha venido instalando una parte importante de la ciencia social 'crítica' de las últimas décadas, sobre todo a raíz del éxito de los estudios culturales y del paso del debate de la posmodernidad al de la globalización (Featherstone \& Lash 1995). La ventaja de recurrir a Soja es que en su obra está muy claro el programa que se quiere poner en marcha; se trata, dice, de:

"la reafirmación de una perspectiva espacial crítica en la teoría y el análisis social contemporáneo. Por lo menos durante el siglo pasado, el tiempo y la historia han ocupado un lugar privilegiado en la conciencia teórica y práctica del marxismo occidental y de la ciencia social crítica. Comprender cómo se hace la

${ }^{14}$ El adjetivo alócrono es utilizado por Fabian (1983: 32) como antónimo de isócrono, significando lo que es de, o se sitúa en, otro tiempo; es la negación más rotunda de la coetaneidad o contemporaneidad. 
historia ha sido la fuente principal de las aproximaciones emancipatorias y de la conciencia política práctica [...] Hoy, sin embargo, puede ser el espacio, más que el tiempo, el que atesora consecuencias para nosotros; la 'producción' [making] de la geografía, más que la de la historia, la que nos proporciona un mundo más revelador tanto en términos tácticos como teóricos” (ibid.: 1).

Queda bien claro qué se entiende por tiempo a abolir o circunscribir; se trata de un tiempo identificado con la historia, que no hace sino identificarla con la emergencia del cambio a partir de la praxis humana. En el marco de ese dominio de lo temporal, dar cuenta de un fenómeno social era tanto como situarlo en una historia contada o a contar. El tiempo es historia que narra los cambios que se suceden. Prescindir del tiempo o resituarlo es tanto como abolir el privilegio del relato histórico. ¡Una pobre concepción del tiempo, de la mano de una pobre concepción de la historia! Por eso se puede decir, sin pérdida alguna, que no se pretende la abolición de lo histórico-temporal, sino su conversión en un paisaje de fondo, obvio y aproblemático, sobre el que pintar un cuadro lleno de vida que dramatiza las relaciones espaciales.

"Proponer que la historia es la materialización de la vida social provocaría escasa controversia, especialmente entre los marxistas. Es algo virtualmente axiomático para el análisis materialista histórico. Pero es en este nivel fundamental, axiomático y ontológico, en el que la espacialidad ha de incorporarse como una segunda contextualización/materialización del ser social. La constitución de la sociedad es espacial y temporal; la existencia social se hace concreta en geografía e historia” (Soja 1989: 127).

Todo vale y ha de conseguir su reconocimiento, pero es la geografía la que se llena de vida más allá de la historia-tiempo, obvia y dada por descontado. Lo que el nuevo giro quiere liberar es la "imaginación espacial" en un mundo en el que, según parece, el tiempo y la historia se han convertido en obstáculos para que surja. La espacialización siempre es ambivalente (espacio/tempo), pero no deja de marcar de forma diferente las dos caras que reconoce ${ }^{15}$.

Esa ambivalencia se reafirma, por ejemplo, en la obra de Arik Darlik (2007). Propone la tarea de hacer una aproximación a la vez histórica y espacial a la modernidad global en la que vivimos, pero primando claramente la perspectiva espacial. Esta apuesta por el espacio se argumenta porque, en una reducción adicional del concepto de tiempo, lo identifica con su obsoleta versión historicista eurocéntrica, es decir, con un proceso unitario y universal de evolución socio-cultural que tiene su centro de irradiación en occidente y se desarrolla de forma continua y homogé-

${ }^{15}$ Algunos partidarios de los estudios culturales llevan su crítica a la modernidad=tiempo hasta el extremo de apostar por una lógica unilateral del espacio sin admitir la posible conciliación que supondría considerar el espacio-tiempo. Véase en este sentido las propuestas ‘fuertes’ de Grossberg (2003: 170-1). 
nea por todo el planeta. De este modo, cada sociedad ocuparía un lugar más o menos cercano/lejano del origen o de la meta. En contra, Darlik objeta que el proceso de globalización, una vez alcanzada su actual fase, es un proceso sin dirección temporal universal prefijada que actúe de forma continua. Hay que describirlo mejor en términos espaciales -de ahí el 'spatial turn'- en el marco de conceptos como fragmentación, descentramiento, integración-homogeneización, separacióndiversificación-diferenciación, pluralidad de modernidades, etc. (Darlik 2007: 20 ss.). De este modo, lo importante no es la dirección en el tiempo de un proceso unitario, sino la distribución por el espacio de los elementos de un proceso heterogéneo. La globalización invita a pensar la contemporaneidad de lo heterogéneo, más que su sucesión en el tiempo. En concreto, "la modernidad global se caracteriza por la contemporaneidad temporal, lo que la distingue de la anterior modernidad eurocéntrica” (ibid.: 94-5). Y esto significa que no hay superiores/inferiores; que las diferencias no se pueden conceptuar en términos temporales (adelantados/retrasados); que, simplemente, coexisten en el espacio modernidades diferentes que se condicionan entre sí, dependen de, o se engendran, las unas a las otras sin que unas fijen el porvenir o futuro de las otras. Hay muchas tradiciones o legados que son compatibles con la modernidad en su fase actual de modernidad global una modernidad sin teleología, puramente espacial.

De nuevo, el enriquecimiento del análisis espacial va de la mano del empobrecimiento del lenguaje temporal. El tiempo y la temporalización del ser que intentaron los modernos se identifican sin más con el monstruo que quitaba el sueño a Popper: el historicismo. El mundo de la ciencia social se concibe como un contenedor de escaso tamaño en el que si se mete mucho espacio hay que quitar algo de tiempo. Implícitos de este tipo se encuentran incluso en la obra de Doreen Massey que, como se hace evidente en sus escritos más allá de cualquier duda, aboga por la superación del dualismo espacio/tiempo y una convergencia de los respectivos saberes: hay que acabar con la guerra que enfrenta a Kronos-kairos y Khora-topos. Frente a esto, Massey (2005: 56) reivindica "la necesidad mutua del espacio y el tiempo. La vitalidad del mundo se apoya en ambos, necesariamente juntos”. Más adelante habrá ocasión de volver sobre esta propuesta y reivindicar su pertinencia. Pero lo que todavía llama la atención en su argumentación es el implícito que enriquece el análisis espacial y empobrece el temporal, como si en el uno estuviera todo por decir o innovar y en el otro todo ya visto y dicho. El tiempo es el cambio; el espacio, por el contrario algo mucho más complejo y, desde luego, algo lejano de las ideas tópicas (lejos/cerca, dentro/fuera, al lado/separado de): una esfera en la que se entrelazan un mundo relacional, heterológico y simultáneo; o en una de sus formulaciones sintéticas una "simultaneidad de trayectorias múltiples" (ibid.: 61). Esa apuesta por el espacio, tendría, además, la virtud de desatar efectos emancipatorios:

“la espacialización de la teoría social y del pensamiento político puede llevar a imaginar un más pleno reconocimiento de la simultánea coexistencia de los otros con sus propias trayectorias y sus propias historias que contar” (ibid.: 11). 
No se entiende la razón por la que un análisis emancipatorio, atento a la simultaneidad, las trayectorias y las historias que lo heterogéneo ha de contar, es propiamente espacial y no más bien temporal o, en cualquier caso, espacio-temporal. ¡El espacio muerto ha resucitado para quedarse con la herencia crítico-emancipatoria de que un día disfrutara el tiempo! Afortunadamente, al final siempre llega un salvador; es cuestión de esperar despiertos.

\section{5. ¿Un tiempo enfermo?}

En las anteriores secciones se ha procedido a una lectura selectiva de una literatura desbordante. Se ha pretendido mostrar, centrándose en unos cuantos casos, de qué modo una mayor atención al tiempo, o una ciencia social temporalmente más reflexiva, desemboca en la paradoja de dar por muerto o seriamente enfermo aquello a lo que se parecía atender. Evidentemente, ese tiempo que se diagnostica enfermo (o de sobra o auto-contradictorio) se dice de muchas maneras, es decir, tiene una semántica compleja. No puedo aquí desentrañarla. Me limito a apoyarme en una tradición multisecular y rebosante de auctoritas, que ha sido reconstruida en los trabajos de referencia de Ricoeur (1983-5) o Blumenberg (1996). Esa tradición asegura que el tiempo se dice de dos maneras o como una combinación compleja de ambas: o es tenido por tiempo de la conciencia o de la vida, y se constituye en lo que McTaggart (1968) llamara la Serie A; o se presenta como tiempo del cosmos o del mundo, constitutivo de su Serie B. Sea lo uno, sea lo otro, sea la combinación de ambos, esa dualidad no se puede reducir a una de sus caras ${ }^{16}$. En consecuencia, todo lo que se diga sobre el tiempo social o se refiere a una de esas caras o a ambas a la vez. También lo que se diagnostica sobre sus enfermedades, auto-negaciones o desapariciones. La problemática de la atemporalidad atiende a la Serie B; la del presentismo a la Serie A; la de la espacialización a ambas a la vez. En el primer caso, se dice que el tiempo falta porque no dura, no está ordenado, es instantáneo, carece de dimensiones, no es continuo, etc.; en el segundo, su ausencia se marca por su reducción a uno de sus momentos, el presente; en el tercero, ya se pasa a decir sin más que el tiempo, todo el tiempo, o falta -porque el mundo se ha espacializado- o sobra porque dificulta, o interfiere negativamente en, la descripción y el análisis de lo social.

No todos alcanzan estas conclusiones. Es muy obvio que la sociología temática y sustantivamente temporalizada de las últimas décadas no coincide universalmente en levantar el acta de defunción del tiempo. Pero siendo esto cierto, no lo es menos

${ }^{16}$ Una especificación de esta propuesto sobre la dualidad constitutiva del tiempo se puede encontrar en Ramos (1992). En un sentido cercano se puede atender a lo expuesto en Ramos (2006) y las referencias allí recogidas. 
que tiende de manera suficientemente generalizada hacia ese diagnóstico. ¿Por qué y a qué precio?

Marx no era Dante; no le tentaba escribir el canto del infierno capitalista. A algunos de sus seguidores o, en términos generales, a los impulsores de una ciencia social crítica no les ocurre otro tanto. Una parte significativa de la ciencia social (sociología, antropología, historiografía, geografía, epistemología social) del tiempo aparece bajo el envoltorio de ciencia crítica y no ha sabido superar la tentación de presentar el mundo que analiza como 'tierra del mal'. Como tal, resulta una realidad infernal, poblada de demonios en la que todo lo que tiene valor está en ruina y entre esos bienes el que aquí interesa: la historia, el tiempo en su conjunto, la duración, el presente, el futuro o el pasado. Ya Adorno (1966 y 1985) fue víctima del fácil recurso a Satán: su sociología de la nueva música era la palanca para retratar la desaparición del tiempo, el acontecimiento, el futuro, la continuidad, como rasgos del mundo del capitalismo desaforado en que vivía. Desde entonces, este tema se repite. Lo que procediendo así se gana en términos de condena moral y tremendismo estético, se pierde en capacidad analítica. La crítica no debería ser ni angélica ni satánica; debería limitarse a ser analítica y pragmáticamente esclarecedora.

Pero no se trata tan sólo de los desvaríos de algunas variantes de la teoría crítica. En el fondo, la empresa de la sociología ha sido desde siempre una respuesta del logos a la percepción en términos de pathos del mundo contemporáneo. Su función -por lo menos una de las fundamentales- es alarmar. ¿Qué mayor alarma que la que dice que el tiempo y el espacio han desaparecido y lo demuestra con los datos en la mano? También Durkheim alarmaba diciendo que nos habíamos quedado huérfanos de normas y de dioses; o Weber, asegurando que estábamos encerrados en una carcasa de hierro que asfixiaba el sentido. No hay más que dar otro paso en la misma senda para alcanzar la conclusión de que el tiempo (y el espacio) también han desaparecido, y que somos huérfanos radicales, pues todo nos falta; en realidad, hincamos firmemente los pies sobre la nada.

No entro en la pragmática de la alarma o de la teoría crítica. No me interesa calibrar para qué y hasta qué punto sirven para enfrentar el mundo. Quiero únicamente someter a evaluación los fundamentos lógicos y empíricos de los diagnósticos reseñados. Esa evaluación conduce a proponer un conjunto de razones que fundamentan el rechazo de esa deriva de la sociología del tiempo. Enumeraré algunas.

Primera razón: el tiempo social no se puede reconducir a una matriz unitaria. El error de las sociologías del tiempo reseñadas radica en proponer un cambio en el tiempo social que se puede reducir a un modelo único o dominante. De este modo, tras un período (modernidad, primer capitalismo, sociedad sólida, etc.) en el que regía la disciplina temporal, el orden en las secuencias, el 'tiempo del reloj' y la futurización sistemática de los horizontes temporales, surgiría otro en que todo eso es sustituido total o sustancialmente por una temporalidad tan paradójica, que se niega a sí misma. La idea que informa esa propuesta es la de un tiempo unitario que domina cada estadio epocal del cambio social. Se enfrenta, como tal y sin ser plenamente consciente de ello, a la hipótesis de la pluralidad del tiempo social. Esa hipótesis es constitutiva de la sociología del tiempo: si el tiempo fuera siempre el 
mismo (universal, necesario, absoluto) no tendría sentido construir una sociología que lo tematizara ${ }^{17}$. Esto ha sido afirmado desde la época de los durkheimianos y ha conocido múltiples maneras de concretarlo (véase Adam 1990 o Valencia 2007). Esa pluralidad es tanto diacrónica como sincrónica -y son ambas caras las que hay que considerar. Por un lado, va de la mano del cambio social. Esto es indudable: suponemos así que las transformaciones sociales producen, son soporte de y se estabilizan gracias a nuevas semánticas y prácticas temporales. De este modo, y tal como han hecho los historiadores, podemos dar cuenta del tiempo de la Iglesia, del mercader, del príncipe, de la fábrica, etc. (Le Goff 1983; Thompson 1979), como semánticas y prácticas temporales que se suceden y sustituyen en el devenir histórico. Ahora bien, sería un error pretender que las sociedades complejas se estructuran a partir de un único tiempo y que la historia no es sino el sucederse de mundos socio-culturales de prácticas y semánticas temporales unitarias. Por el contrario, basta con que se sobrepase un umbral mínimo de complejidad social para asistir a la coexistencia de tiempos distintos, cuyas relaciones pueden pensarse de maneras distintas $^{18}$, pero sin ceder a la tentación de reducirlos o derivarlos de una matriz unitaria. De ahí que la pluralidad sea diacrónica y sincrónica. El error de la sociología del tiempo analizada consiste en desconocer esto, forzando la universalización de tiempos particulares o de ámbito de pertinencia circunscrito. Lo que es un tiempo, con un ámbito de pertinencia a determinar, se convierte en el tiempo.

Segunda razón: El cambio no se puede confundir con la desaparición y el vacío. Tilly (1991) advirtió y criticó de manera ejemplar la tendencia de la sociología hegemónica del cambio social a identificar sin más el cambio con el desorden y el vacío, suponiendo que el cambio de algo (y tanto más si eso es de primer orden de importancia) comporta caída, vacío y desaparición -a la espera de que lo caído se alce, el vacío se colme y lo desaparecido reaparezca o sea sustituido por algo. De ahí esa tendencia a convertir la sociología del cambio en una sociología de la orfandad. La sociología del tiempo no ha sabido resistirse a esta tentación -tal vez en razón de su pasión por la alarma. En consecuencia, la aparición de una nueva experiencia de la simultaneidad o el acceso a una comunicación instantánea o la aceleración que estrecha el presente se han convertido en expresiones de un vacío que produce la desaparición del tiempo o su conversión en un oxímoro de difícil gestión. De un modo que no deja de sorprender, tales aseveraciones parecen desconocer lo que es obvio: que la simultaneidad es una relación ordinal temporal (tanto como la sucesión); que la instantaneidad es también una experiencia temporal; que el estre-

${ }^{17}$ Por lo demás, no hace falta situarse en la perspectiva sociológica (o de las ciencias sociales o humanas en general) para alcanzar esta conclusión. También las ciencias ‘duras’ lo proponen. Véase Fraser (1980).

${ }^{18}$ En Nowotny (1992b: 424), Wood (2008: 272-4) y Hutchings (2008: 166) aparecen tres formas distintas de concebir esas relaciones: como pura pluralidad, como jerarquía o como hibridación (heterotemporalidad). 
chamiento o puntualización del presente es un tópico que ya se encuentra en Aristóteles y desde luego es central en S. Agustín, sin que por ello ni el uno ni el otro hayan concluido que el tiempo en la Grecia del siglo IV a.n.e., o en la Roma del siglo V, se hubiera hecho atemporal o hubiera desaparecido, sustituido o no por el espacio. En consecuencia, la sociología del tiempo debe ponerse a la tarea de desentrañar qué nuevas semánticas y prácticas temporales se ponen en marcha con la aceleración, la instantaneidad o la simultaneidad -por limitarnos a estos tópicos tan de esta época.

Tercera razón: El tiempo es constitutivamente problemático porque pone junto lo que es discordante o hasta contradictorio. No es posible desarrollar cabalmente esta tesis fuerte, pero cabe remitirse a los análisis de Ricoeur o de Marramao para encontrar los argumentos que la fundamentan. Marramao (2008: 89-94), en concreto, brinda una pista etimológica esclarecedora: el griego kairos y el latín tempus tienen un origen etimológico común cuya semántica es la de temperar, concordar, acordar, mezclar o poner juntos elementos diversos. De ahí las tensiones del tiempo (repetir/cambiar; perseverar/desaparecer, continuar/interrumpir; empezar/acabar, etc.) y su función de acordador de desacuerdos ${ }^{19}$. En razón de esto, a la hora de desarrollar una sociología del tiempo, hay que tomar en consideración las experiencias discordantes que el tiempo acuerda. Por lo tanto, el orden de lo efímero, lo fugaz o lo cambiante debe ser considerado en sus complejas relaciones con lo duradero, lo perenne o lo permanente. Si, como han destacado distintos analistas, las aceleraciones sociales comportan desaceleraciones (Rosa 2003), la inquietud quietudes (Bissell \& Fuller 2009), las movilidades inmovilidades (Urry 2007), la amnesia hipermnesia (Connerton 2009), la destemporalización retemporalización (Leccardi 2009) y los contactos instantáneos, contratos y compromisos estables (Bressand \& Distler 2003), entonces no parece sensato limitar el análisis y menos el diagnóstico final a uno de esos aspectos, por muy llamativo que sea, a costa de ocultar su compleja relación con los que lo niegan o atemperan. En consecuencia, el análisis que desvela la problematicidad del tiempo ha de abstenerse de identificarla sin más con su desaparición. Es innegable que la complejidad del tiempo lo hace siempre problemático -ya el proto-héroe Gilgamés, rey de Uruk, se quejaba de esto en una época tan remota como el 2650 a.n.e.-, pero esa complejidad, lejos de destruirlo, lo alimenta.

Cuarta razón: Carece de sentido afirmar que el tiempo sea atemporal. Si vamos más allá de las imágenes y reclamos publicitarios y nos atenemos a lo que podemos observar y analizar, entonces hemos de admitir que no es posible ningún mundo social (sea concebido como un sistema o como un entorno de la acción) en el que la complejidad no sea reducida en términos temporales, es decir, estableciendo secuencias, asignando duraciones, fijando principios y finales, acordando calendarios,

${ }^{19}$ En este plano es ejemplar la lectura de Las Confesiones agustinianas realizada por Ricoeur (1983: 19 ss.). 
relojes y agendas (temporalización en términos de la serie B). Que esto no suceda siempre y en todo caso o de la misma manera, no supone que no ocurra nunca o que haya dejado de ocurrir en el campo fundamental de nuestra experiencia. De nuevo, hay que partir del reconocimiento de la complejidad y problematicidad de los acuerdos temporales. Ya hace muchos años Lewis y Weigert (1992) plantearon un esquema (jerarquía, encaje y sincronización temporales) para reducir esa complejidad, que sigue siendo operativo. Los resultados que se obtienen trabajando en ese marco analítico son superiores a los que se alcanzan postulando el hundimiento del marco temporal de la acción. En definitiva, el tiempo del entorno de la acción se configura de muchas maneras, pero no desaparece.

Quinta razón: el proceso de constitución del tiempo ocurre siempre partiendo del presente -lo que ni significa ni presupone que se quede encerrado en él. Mead (1980) lo destacó poderosamente. Deberíamos seguir sus indicaciones. El presente se puede constituir de muchas maneras. Ya se pudo atender anteriormente a la lista de sus adjetivaciones en la ciencia social contemporánea que, de alguna manera, denotan las múltiples conformaciones a que está abierto. Una de ellas es aquella que lo encierra en sí mismo, desgajándolo de sus horizontes temporales. Que eso sea para bien (el gozo del deslizarse por una realidad convertida en moda) o para mal (la angustia de no poder asir nada) es lo de menos. Lo relevante es que un presente así niega otras posibilidades que son tanto o más actualizables. Piénsese en una idea (muy cercana a ésta) propuesta por Helga Nowotny (1992): la idea de un presente extenso. En él, la primacía del presente como experiencia supone la inclusión en su ámbito de horizontes de futuro que tienen un estatuto ambiguo: son y no son de ahora; se sitúan más lejos del presente, pero ya están conformándose ahora. Es así como se reconstruye ese complejo trabajo con la crisis ecológica del futuro al que se asiste en la actualidad. En términos semejantes ha argumentado últimamente Barbara Adam en su libro conjunto con Groves (Adam \& Groves 2007). Se trata sólo de un ejemplo, escogido por estar cerca de la idea de un presente encerrado en sí mismo. Más allá se sitúa lo que desde S. Agustín se ha venido pensando sobre la constitución de los horizontes temporales. El presentismo sólo hace referencia a la primacía del presente, no a la imposibilidad de constituir los horizontes del futuro y del pasado. Hay pues que atender a cómo se integran éstos en el presente y cómo se consolidan lo que, ya hace mucho, Nuttin (1985) denominó las actitudes, orientaciones y perspectivas temporales.

Sexta razón: el problema no es 'o tiempo o espacio'. Ni vivimos en la época del fin del espacio, ni en la del fin del tiempo, ni tampoco es preciso atender exclusiva o preferentemente a uno u otro para hacerla inteligible. Es, pues, estéril abordar el diagnóstico de nuestra época contraponiéndolos, como si estuviéramos ante una alternativa en la que hay que elegir ${ }^{20}$. En realidad, como propone Massey,

${ }^{20}$ Sobre el tema, la literatura y los debates sobreabundan. Como muestra, véanse Dodgshon (1999), Jessop (2009), Low \& Barnett (2000), Massey (2005), Sheppard (2002). 
"el tiempo y el espacio no son reductibles el uno al otro; son distintos, pero están co-implicados. En el campo del espacio, hay una temporalidad integral de una simultaneidad dinámica. En el campo del tiempo, hay una necesaria producción de cambio a partir de prácticas de interrelación” Massey (2005: 55)

Esta mutua implicación se muestra de muchas manera: no hay más que pensar en el viejo arte de los topoi o loci de la memoria (Yates 1974) y en los resultados de la sociología de la memoria y del olvido de Connerton (2009) -que, como se apuntó antes, presenta el lugar como preservador y condición de la memoria. Esto es cierto, pero esta imbricación y mutua dependencia no ha de llevar a concebirlos como simples variantes de lo mismo o indiscernibles; son, en realidad, aspectos diferentes y no traducibles. De ahí que el spatial turn acabe desembocando en un temporal return (Jessop 2009: 135): ida y vuelta, vuelta e ida. Para algunos (Castree 2009), esta insustituibilidad significa que sólo se debería hacer análisis espacio-temporal o, lo que es lo mismo, que un análisis que atienda sólo al tiempo, o sólo al espacio, no sólo es insuficiente, sino además erróneo. No me convence esta propuesta. $\mathrm{Si}$, como es obvio, no es necesario dar cuenta de todo para dar cuenta de algo, tampoco en este caso es necesario dar cuenta del espacio-tiempo en su conjunto para analizar y aclarar los aspectos temporales o espaciales de algo. El análisis espacial o temporal de los fenómenos sociales es más que legítimo, con tal de que no se pretenda agotador de su inteligilidad o suficiente. Lo que se debe intentar es hacer más complejo, rico y esclarecedor el uno y el otro. De nada vale una sociología pobre en términos temporales y sofisticada en términos espaciales; es preciso que lo sea en los dos planos. En consecuencia, nada hay que objetar a una sociología del espacio-tiempo, pero tampoco a una sociología del tiempo o del espacio.

Séptima razón: hay que dar por cerrada la cibérbole sociológica. El término lo ha propuesto, con ingenio y acierto, Woolgar (2006) y se refiere a la hipérbole cibernética. Llevamos ya dos décadas de alucinación sociológica con las TICs. Deberíamos ya celebrar sus funerales e invitar a sus mentores a un prudente retiro. La cibérbole ha sido especialmente perniciosa en los estudios contemporáneos sobre el tiempo social. Siguiendo un tópico sólidamente asentado en los mass media, se ha presentado el cambio tecnológico y especialmente la revolución cibernética como si comportara inmediatamente un cambio en la gramática del espacio-tiempo -un espacio-tiempo ya inscrito y prefigurado en sus tecnologías y tan sólo a la espera de la oportunidad de desplegarse. Las declaraciones programáticas en contra del tópico se han sucedido, pero acompañadas a renglón seguido de prácticas de construcción del conocimiento que lo entronizan. En esto no hemos hecho sino dejarnos seducir por la fantasía sobre los efectos espacio-temporales de las nuevas tecnologías del transporte y la comunicación que se disparara ya en el primer tercio del XIX, en los tiempos de la aparición del ferrocarril. Al poco de la inauguración de las primeras líneas, se sucedieron las advertencias sobre el asesinato del tiempo y del espacio (Koselleck 2007). Lo mismo ocurrió, a principios de siglo XX, tras el triunfo de la muy humilde bicicleta que, a decir de sus críticos, llevaba con su velocidad a la disolución de todos los lazos sociales (Kern 1983: 111-3). Como no 
podía ser menos, también el telégrafo y el teléfono lo iban a cambiar todo (Marvin citado en Graham 1998: 169). Dejemos aquí los ejemplos que se podrían multiplicar sin tasa. Hablan de la alucinación tecnológica tan característica de la modernidad. En lo que a la cibérbole se refiere, no dudo de la relevancia de las nuevas tecnologías de la información y la comunicación. Es muy obvia. Tampoco me parece objetable que la sociología esté atenta a sus impactos espacio-temporales. Lo que sí se puede exigir es un poco más de prudencia en los vaticinios y una mayor atención a lo que los actores sociales hacen realmente cuando las utilizan o se dejan utilizar por ella. Lo que parece apresurado e insostenible es proclamar a bombo y platillo que esas tecnologías hayan hecho, sin más y en unos pocos años, líquido lo sólido, instantáneo lo duradero, quebrado lo entero, desaparecido lo presente, muerto lo vivo y atemporal el tiempo. En contra de estos tópicos entre ingenuos y dogmáticos, hay que repetir lo que todos deberíamos saber y Wajcman (2008: 12), una buena estudiosa del tema, nos recuerda y es que "no hay una lógica temporal inherente en un artefacto que determine las prácticas temporales".

\section{Conclusiones/remisiones.}

Es obvia la conclusión que se alcanza. El destino de la sociología del tiempo puede eludir la paradoja que parece atenazarla. ¿Cómo? Evitando las síntesis de conjunto más bien apresuradas e invirtiendo preferentemente en la investigación empírica. Es justo reconocer que esto se lleva tiempo haciendo. Basta con considerar las investigaciones sobre el ciberespacio (Carter 2005, Graham 1998, Kitchin 1998, Pratt, 2000) o sobre la comunicación por medio de móviles (Green 2002, Licoppe 2004, Prasopoulou, Pouloudi \&Panteli 2006; Wajcman 2008). Lo que alienta en esas líneas de investigación es que, para dar cuenta de las nuevas vivencias del espaciotiempo o de cómo las tecnologías median nuestra relación con el mundo, se atiende, no a lo que supuestamente está ya inscrito en las tecnologías, sino a las prácticas de los actores. Es evidente que esas prácticas no son soberanas, pues el mundo no es una masa de plastilina moldeable a voluntad. Pero siendo esto cierto, y siendo muy prometedora la aproximación al estudio de estos fenómenos que siguen las indicación de la teoría del actor-red (Hörning, Ahrens \& Gerhard 1999), no lo es menos que son los actores, haciendo y deshaciendo, los que resuelven los problemas de estructuración temporal que enfrentan -lo hacen, sepan o no lo que hacen. No se trata de un mundo intencional, sino práxico.

Pero, aunque necesaria, la investigación empírica no basta. Es preciso dar pasos en la teoría del tiempo social. No se pueden dar aquí, pero se pueden establecer orientaciones sobre su posible dirección. Hay que partir del reconocimiento de la dualidad constitutiva a la que se hizo referencia en páginas anteriores. En ese marco, se precisa, además, una teoría del tiempo social que resuelva un doble problema y la articulación de las respectivas soluciones. El primero se puede denominar problema de Ricoeur-Blumenberg y se define como el de la inserción del tiempo de la vida humana en el tiempo del cosmos externo (material, social). La pregunta estratégica 
es: ¿Con qué recursos temporales cuenta un actor social, que es también tiempo incorporado, para lograr insertarse en el entorno temporal de horarios, plazos, secuencias, duraciones, etc.? El segundo problema es el de Agustín-Luhmann y hace referencia a la integración de los horizontes temporales en el presente de la acción. La pregunta estratégica se puede enunciar así: ¿Cómo se puede configurar y mantener en el presente de la acción un doble horizonte pasado-futuro que permita hacer plausible una identidad que se despliega en el tiempo? Estos son los dos problemas que ha de abordar la teoría del tiempo ${ }^{21}$. Sus respectivas soluciones deberán compatibilizarse.

${ }^{21}$ Sobre el significado del tiempo como 'recurso', como ‘entorno', como “tiempo incorporado’ y como ‘horizonte’, véase Ramos (2007 a y b). 


\section{Bibliografía}

Adam, B. (1990) Time and Social Theory. Cambridge, Polity.

Adam, B. (1995) Timewatch. The Social Analysis of Time. Cambridge, Polity Press.

Adam, B. (1998) Timescapes of modernity: the environment and invisible hazards. London, Routledge.

Adam, B. (2004) Time. Cambridge, Polity Press.

Adam, B. y Ch. Groves (2007) Future matters: action, knowledge, ethics. Leiden, Hill.

Adorno, T. (1966) Filosofía de la nueva música. Buenos Aires, Losada.

Adorno, T. (1985) Impromptus. Barcelona, Editorial Laia.

Baier, Lothar. (2002) Pas le temps!: traité sur l'accéleration. Arles : Actes Sud.

Bauman, Z. (2000) Liquid Modernity. Cambridge, Polity Press.

Bauman, Z. (2001) La posmodernidad y sus descontentos. Madrid, Akal.

Beriain, J. (2008) Aceleración y tiranía del presente. Barcelona, Anthropos.

Bertman, S. (1998) Hyperculture The human cost of speed. Westport (CT): Praeger.

Bissell, D. \& G. Fuller (2009) “”'The revenge of the still” M/C Journal 12 (1) htpp://journal.media.culture.org.au/index.php/mcjournal/article/view/136

Blumenberg, H. (1996) Tempo della vita e tempo del mondo. Bologna, Il Mulino.

Bressand, A. y C. Distler (2003) "Il tempo dell'economia : collisioni di orizzonti o coerenze negoziate?” en D. de Kerckhove (ed.), La conquista del tempo: società e democrazia nell'era della rete. Roma: Editori Riuniti:61-74.

Breuer, Stefan (2009) "The nihilism of speed: on the work of Paul Virilio" en H. Rosa \& W.E. Scheuerman (eds.), High-Speed Society: Social Acceleration, Power and Modernity. Pennsylvania, Pennsylvania State University: 215-41.

Brodowsky, G., Granitz, N. y B. Anderson (2008) "The best of times is now. A study of the gay culture's attitudes toward time” Time and Society $17(2 / 3)$ : 233-260.

Carter, Denise (2005) "Living in Virtual Communities: An Ethnography of Human Relationships in Cyberspace” Information, Communication \& Society, vol. 8, no. 2, pp. 148-167.

Castells, M. (1997) La era de la información: economía, sociedad y cultura. Volumen 1: La sociedad red. Madrid, Alianza.

Castells, M, Fernandez-Ardevol, M, Qui, J.L. \& A. Sey (2006). C Comunicación móvil y sociedad: Una perspectiva global. Barcelona, Ariel.

Castree, (2009) “The spatio-temporality of capitalism” Time \& Society 18, 1: 26-61.

Connerton,P. (2009) How Modernity Forgets. Cambridge, Cambridge University Press.

Connolly, William E. (2000) "Speed, concentric cultures and cosmopolitanism" Political Theory 28 (5): 596-618.

Dirlik, Arif 2007) Global Modernity. Modernity in the Age of Global Capitalism. Boulder: Paradigm Publisher. 
Dodgshon, Robert A.(1999) "Human geography at the end of time? Some thoughts on the notion of time -space compression” Environment and Planning D: Society and Space 17: 607- 620.

Durkheim, E. (1968) Les formes élémentaires de la vie religieuse. Paris, PUF.

Fabian, J. (1983) Time and the Other. How Anthropology Makes his Object. New York, Columbia University Press.

Featherstone M \& S. Lash (1995) "Globalisation, modernisation and the spatialisation of social theory: an introduction", in M Featherstone, S Lash, R Robertson (eds.) Global Modernities London: Sage: 1- 24.

Fraser, J.T. (1980) "Out of Plato's Cave: the Natural History of Time" The Kenyon Review, 2, 1: 143-162.

Graham, Stephen (1998) "The end of geography or the explosion of place? Conceptualizing space, place and information technology" Progress in Human Geography 22 (2): 165-185.

Green. N. (2002) "On the move: technologies, mobility and the mediation of social time and space” The Information Society 18: 281-92.

Grossberg, Lawrence (2003) "Identidad y estudios culturales: ¿no hay nada más que eso?” en S. Hall y P. du Gay (eds.), Cuestiones de identidad cultural. Buenos Aires, Amorrortu: 148-180.

Harvey, D. (1998) La condición de la posmodernidad. Buenos Aires, Amorrortu.

Hörning, K.H., Ahrens, D. y A. Gerhard (1999) "Do technologies have time? New practices of time and the transformation of communication technologies" Time \& Society 8 (2): 293-308.

Hutchings, Kimberly (2008) Time and world politics. Thinking the Present. Manchester, Manchester University Press. [UCM: Políticas].

Jameson, F. (1995) El posmodernismo o la lógica cultural del capitalismo. Barcelona, Paidós.

Jameson, F. (2000) Semillas del tiempo. Madrid, Trotta.

Jameson, F. (2003) "The End of Temporality" Critical Inquiry, Vol. 29, No. 4 (Summer): 695-718.

Jessop, Bob (2009) "The spatiotemporal dynamics of globalizing capital and their impact on state power and democracy" en H. Rosa \& W.E. Scheurman (eds.), High-Speed Society: Social Acceleration, Power and Modernity. Pennsylvania, Pennsylvania State University: 135-158.

Kerckhove, Derrick de (ed.) (2003) La conquista del tempo: società e democrazia nell'era della rete. Roma : Editori Riuniti.

Kern, S. (1983) The Culture of Time and Space, 1880-1918. Cambridge (Mass.), Harvard University Press.

Kitchin, Robert M. (1998) "Towards geographies of cyberspace” Progress in Human Geography 22, (3): 385-406.

Koselleck,R. (1985) Futures Past. On the Semantics of Historical Time. Cambridge (Mass.), MIT Press. 
Koselleck,R. (2007) “¿Existe una aceleración de la historia?” en J. Beriain y M. Aguiluz (eds.), Las contradicciones culturales de la modernidad. Anthropos, Barcelona: 319-345.

Laïdi, Zaki. (2000) Le sacre du présent. Paris : Flammarion.

Lash S. y J. Urry (1994) Economies of signs and space. London, Sage.

Le Goff, J. (1983) Tiempo, trabajo y cultura en el occidente medieval. Madrid, Taurus.

Leccardi, C. (2009) Sociologie del tempo. Bari: Laterza.

Lévi-Strauss, Claude (1962) La pensé sauvage. Paris, Plon.

Lewis, J.D. y A.J. Weigert (1992)"Estructura y significado del tiempo social" en R. Ramos (comp.) Tiempo y sociedad, Madrid, CIS: 89-131.

Licoppe, Christian. (2004) "Connected' presence: the emergence of a new repertoire for managing social relationships in a changing communication technoscape” Environment and Planning D: Society and Space, 22: 135 -156.

Lipovetsky, G. (1990) El imperio de lo efímero. La moda y su destino en las sociedades modernas. Barcelona, Anagrama.

Lipovetsky, G. (2006) Los tiempos hipermodernos. Barcelona, Anagrama.

Low, M. y C. Barnett (2000) “After globalization” Environment and Planning D: Society and Space 18: 53-61.

Lübbe, Hermann (2009) "The contraction of present» en H. Rosa \& W.E. Scheurman (eds.), High-Speed Society: Social Acceleration, Power and Modernity. Pennsylvania, Pennsylvania State University: 159-178.

Luhmann, N. (1976) "The Future Cannot Begin: Temporal Structures in Modern Society" Social Research 43: 130-52. (trad. en R. Ramos (comp.), Tiempo y sociedad, Madrid, CIS, 1992: 161-182).

Maffesoli, Michel (1985) L'ombre de Dyonisos. Contribution à une sociologie de l'orgie.Paris, Librairie de Méridiens.

Maffesoli, Michel (1996) Eloge de la raison sensible.Paris, Grasset.

Maffesoli, Michel (2000) L'instant éternel. Le retour du tragique dans les sociétés postmodernes. Paris, Denoël.

Marramao, Giacomo (2008) La passione del presente. Torino, Bollati Borringhieri Editore.

Martins, H. (1992) "Tiempo y teoría en sociología" en R. Ramos Torre (comp.), Tiempo y Sociedad. Madrid, CIS: 183-242.

Massey, Doreen (2005) For Space. London, SAGE.

McTaggart, J.M.E. (1968) "Time” en R.M. Gale (ed.), The Philosophy of Time, New Jersey, Humanity Press : 86-97.

Mead, G.H. (1980) The philosophy of the present, Chicago, Un. of Chicago Press $\left(1^{\circ}\right.$ ed. 1932$)$.

Nowotny, H. (1992) Le temps à soi: génèse et structuration d'un sentiment du temps. Paris, Editions de la Maison des Sciences de l'Homme.

Nowotny, H. (1992b)"Time and social theory: towards a social theory of time" Time \& Society 1 (3): 421-54. 
Nuttin, J. (1985) Future Time Perspective and Motivation. Theory and Research Method. Louvain, Presses Universitaires de Louvain.

Prasopoulou, E.; Pouloudi, A. y N.Panteli (2006) "Enacting new temporal boundaries: the role of mobile phones” European Journal of Information Systems (2006) 15, 277-284.

Pratt, Andy C. (2000) "New media, the new economy and new spaces" Geoforum 31: 425-436.

Ramos Torre, Ramón (1992) “Introducción a R. Ramos Torre (compilador),Tiempo y sociedad CIS, Madrid vi-xxiii.

Ramos Torre, Ramón (1995) "Ocho tesis sobre la estructura temporal de las sociedades contemporáneas” Papeles de la FIM n 3 (2 $2^{\mathrm{a}}$ época): 77-90

Ramos Torre, Ramón (1998) "El desvanecimiento de Cronos: aspectos de la temporalidad en las sociedades actuales" en AA.VV., El malestar urbano en la gran ciudad, Madrid, Talasa: 33-44.

Ramos Torre, Ramón (1999) "Red, identidad, espacio y tiempo: algunas observaciones sobre La era de la Información de Manuel Castells” Revista Española de Investigaciones Sociológicas 86: 379-386.

Ramos Torre, Ramón (2006) “Time’s Social Discourses” Kronoscope. Journal for the Study of Time. 6 (2):231-247.

Ramos Torre, Ramón (2007a) "Metáforas sociales del tiempo en España: una investigación empírica” en Carlos Prieto (ed.) Trabajo, género y tiempo social. Editorial Complutense y Editorial Hacer: 173-204.

Ramos Torre, Ramón (2007b) "Presentes terminales: un rasgo de nuestro tiempo" en Juan A. Roche Cárcel (ed.), Espacios y tiempos inciertos de la cultura. Editorial Anthropos: 171-181.

Ramos Torre, Ramón (2009) "El tiempo en la sociología: del círculo virtuoso a la paradoja” en Guadalupe Valencia (coordinadora), El tiempo en las ciencias sociales y las humanidades. Universidad Nacional Autónoma de México. México: 99120.

Ramos Torre, Ramón (2012) “A la contemporaneidad le falta el tiempo. Apuntes sobre la ciencia social actual y su retrato de lo contemporáneo" en J. Gandarilla, R. Ramos y G. Valencia (coordinadores), Contemporaneidad(es). Madrid: Sequitur: 63-76.

Ricoeur, P. (1983-5) Temps et récit. (vols. I, II y III) Paris, Seuil.

Rosa, Harmut (2003) "Social acceleration: ethical and political consequences of a desynchronized high-speed society" Constellations 10 (1): 3-33.

Rosa, H. y W.E. Scheuerman (eds.) (2009) High-Speed Society: Social Acceleration, Power and Modernity. Pennsylvania, Pennsylvania State University.

Sánchez Usanos. D. (2010) "Posmodernidad y experiencia temporal: Fredric Jameson” Cominucación presentada en el GT de Sociología del Tiempo. X Congreso Español de Sociología. Pamplona 2010.

Scheuerman, William. (2004) Liberal Democracy and the Social Acceleration of Time. Baltimore: John Hopkins University Press. 
Scheuerman, William. (2009) "Citizenship and speed” en H. Rosa \& W.E. Scheurman (eds.), High-Speed Society: Social Acceleration, Power and Modernity. Pennsylvania, Pennsylvania State University: 288-306.

Sennett, R. (2000) La corrosión del carácter. Las consecuencias personales del trabajo en el nuevo capitalismo. Barcelona, Anagrama.

Sennett, R. (2006) La cultura del nuevo capitalismo. Barcelona, Anagrama, 2006.

Sheppard, Eric (2002) "The spaces and times of globalization: Place, scale, networks, and positionalitity” Economic Geography 78 (3): 307-30.

Soja, Edward W. (1989) Postmodern Geographies. The reassertion of space in critical social theory. London. Verso.

Thompson, E. (1979) "Tiempo, disciplina de trabajo y capitalismo industrial" en E.P. Thompson, Tradición, revuelta y consciencia de clase. Barcelona, Crítica: 239-93.

Tilly, Ch. (1991) Grandes estructuras, procesos amplios, comparaciones enormes. Madrid, Alianza.

Urry, J. (2007) Mobilities. Cambridge: Polity Press.

Valencia, Guadalupe (2007) Entre cronos y kairós. Las formas del tiempo sociohistórico. Barcelona, Editorial Anthropos.

Virilio, Paul (1984) L'horizon négatif : essai de dromoscopie.Paris : Galilée.

Virilio, Paul (1999 a) La bomba informática. Madrid, Cátedra.

Virilio, Paul (1999 b) El cibermundo, la política de lo peor. Entrevista con Philippe Petit. Madrid, Cátedra.

Wajcman, J. (2008). "Life in the fast lane? Towards a sociology of technology and time" The British Journal of Sociology, 59, 1, 59-77.

Wood, Charles H. (2008) « Time, cycles and tempos in social-ecological research and environment policy » Time and Society $17(2 / 3): 261-82$.

Woolgar, S. (2006) “ ¿Un Internet reflexivo? La experiencia británica de las nuevas tecnologías electrónicas” en M. Castells (ed.), La Sociedad Red: una visión global. Madrid, Alianza Editorial: 168-88.

Yates, F. (1974) El arte de la memoria. Madrid, Taurus. 